\title{
Pengelolaan ekosistem mangrove di muara Sungai Musi sebagai upaya mitigasi emisi karbon
}

\author{
H. Farahisah ${ }^{1 *}$, F. Yulianda ${ }^{2}$, H. Effendi ${ }^{2,3}$ \\ 1Program Studi Pengelolaan Sumberdaya Pesisir dan Lautan, Sekolah Pascasarjana, IPB University, Bogor, \\ Indonesia \\ ${ }^{2}$ Departemen Manajemen Sumberdaya Perairan, IPB University, Bogor, Indonesia \\ 3Pusat Penelitian Lingkungan Hidup, IPB University, Bogor, Indonesia
}

\begin{abstract}
Abstrak.
Salah satu upaya dalam mendukung pengembangan wilayah pesisir adalah melalui pengelolaan ekosistem mangrove. Sumber daya mangrove selain berperan dalam pengembangan ekonomi masyarakat pesisir juga memiliki peranan dalam mitigasi emisi karbon. Penelitian ini bertujuan memberikan gambaran tentang persepsi dan partisipasi masyarakat dan posisi stakeholder dalam pengelolaan lingkungan mangrove di muara Sungai Musi. Penelitian dilakukan di muara Sungai Musi, Kabupaten Banyuasin, Provinsi Sumatera Selatan. Data persepsi dan identifikasi stakeholder didapatkan melalui wawancara responden. Hasil menunjukkan bahwa $>90 \%$ masyarakat mengetahui keberadaan dan fungsi mangrove dan setuju berpartisipasi pada berbagai kebijakan pengelolaan mangrove. Diperlukan suatu upaya agar semua stakeholder menjadi key player dalam pengelolaan mangrove sebagai cadangan karbon di muara Sungai Musi. Rekomendasi pengelolaan untuk peningkatan cadangan karbon diantaranya adalah pemberdayaan dan peningkatan pengetahuan masyarakat sekitar, rehabilitasi hutan dan lahan, pengembangan teknik budidaya agroforestri, pengembangan hasil hutan non kayu dan konservasi tanah dan air.
\end{abstract}

Kata kunci: pengelolaan, mangrove, persepsi dan partisipasi, stakeholder

\begin{abstract}
.
One of the efforts to support the development of coastal areas, is through mangrove management. Besides having a role in the economic development of coastal communities, mangrove also has role as mitigation of carbon emissions. This study aimed to provide an overview of the perceptions and participation of the community and order of stakeholders in the mangrove management at the mouth of Musi River. The research was conducted at Musi River estuary, Banyuasin Regency, South Sumatra Province. Meanwhile, the data of stakeholders perception were derived through respondents' interviews. The results showed that more than $90 \%$ of the community knew mangrove existence and function and agreed to participate in various mangrove management policies. An effort is needed so that all stakeholders become key players in mangrove management as carbon reserves at the mouth of the Musi River. Management recommendations for carbon reserves enhancement include empowerment and improvement of community knowledge, forest rehabilitation and land, development of agroforestry cultivation techniques, development of non-timber forests, also soil and water conservation.
\end{abstract}

Keywords: management, mangroves, perception and participation, stakeholders

\section{PENDAHULUAN}

Mangrove memiliki jasa ekosistem yang sangat penting sebagai penyangga kehidupan diantaranya sebagai habitat aneka biota, daerah penangkapan nelayan, mencegah abrasi air laut, pelindung garis pantai, pengatur iklim mikro dan penyerap karbon (Rachmawati et al. 2014; Suman 2018). Vegetasi mangrove dapat memberikan dampak positif dalam proses penyerapan karbon pada permukaan atmosfer. Hutan mangrove memiliki potensi paling tinggi menjadi cadangan karbon daripada hutan lainnya. Penyimpanan karbon oleh hutan mangrove mencapai 2-3 kali lebih tinggi daripada hutan terestrial (Donato et al. 2011; Kauffman et al. 2011; Adame et al. 2013; Tue et al. 2014). Oleh karena itu,

${ }^{*}$ Korespondensi Penulis

Email : harum_farah@apps.ipb.ac.id 
kerusakan pada ekosistem mangrove memiliki dampak yang jauh lebih besar. Rusaknya hutan mangrove sebesar 1 ha akan melepaskan cadangan karbon yang setara dengan rusaknya 3-5 ha hutan terestrial/konvensional.

Penyumbang emisi karbon di Sumatera Selatan salah satunya berasal dari perubahan tutupan lahan. Penyebab perubahan tutupan lahan beberapa diantaranya adalah adanya kegiatan deforestasi di kawasan hutan primer seperti hutan kering, mangrove dan rawa. Deforestasi dapat berasal dari kebakaran hutan, illegal logging dan pembukaan lahan pertanian oleh masyarakat sekitar kawasan hutan. Salah satu estuari yang berada di Kabupaten Banyuasin Sumatera Selatan adalah muara Sungai Musi. Sungai Musi termasuk sungai terbesar dan terpanjang di Provinsi Sumatera Selatan. Aliran Sungai Musi berhulu dari Pegunungan Bukit Barisan di Provinsi Bengkulu dan bermuara ke perairan Selat Bangka di Desa Sungsang, Kabupaten Banyuasin, Provinsi Sumatera Selatan (BRPPU 2010).

Penelitian terkait stok karbon dilakukan oleh Melki and Isnaini (2014) di wilayah muara Sungai Musi dan Sungai Banyuasin dan diketahui bahwa ekosistem mangrove di wilayah ini dapat dijadikan sebagai mitigasi perubahan iklim. Purwiyanto and Agustriani (2016) menyatakan bahwa secara umum perairan di sekitar Pulau Payung berstatus sebagai penyerap karbon (carbon sink). Menurut data Kesatuan Pengelolaan Hutan Lindung (KPHL) yang bersumber dari citra Landsat dan SPOT 6 tahun 2014, luasan hutan mangrove di wilayah KPHL Banyuasin adalah 44.853 Ha (KPHL 2015). Ekosistem mangrove di muara Sungai Musi berperan sebagai penyangga kehidupan masyarakat di sekitarnya, diantaranya untuk aktivitas perikanan, pengambilan kayu bakar, bahan bangunan, dll. Untuk itu perlu diketahui persepsi dan partisipasi masyarakat terhadap ekosistem mangrove di muara Sungai Musi, serta dirumuskan upaya pengelolaannya. Penelitian ini bertujuan menganalisis peranan pemerintah dan persepsi masyarakat dalam pengelolaan mangrove, sehingga diharapkan upaya pengelolaan ekosistem mangrove di muara Sungai Musi dapat ditingkatkan dalam rangka mitigasi pemanasan global.

\section{METODOLOGI}

\subsection{Lokasi kajian dan waktu penelitian}

Penelitian dilaksanakan di wilayah muara Sungai Musi, Sumatera Selatan pada bulan April-Mei 2019 (Gambar 1). 


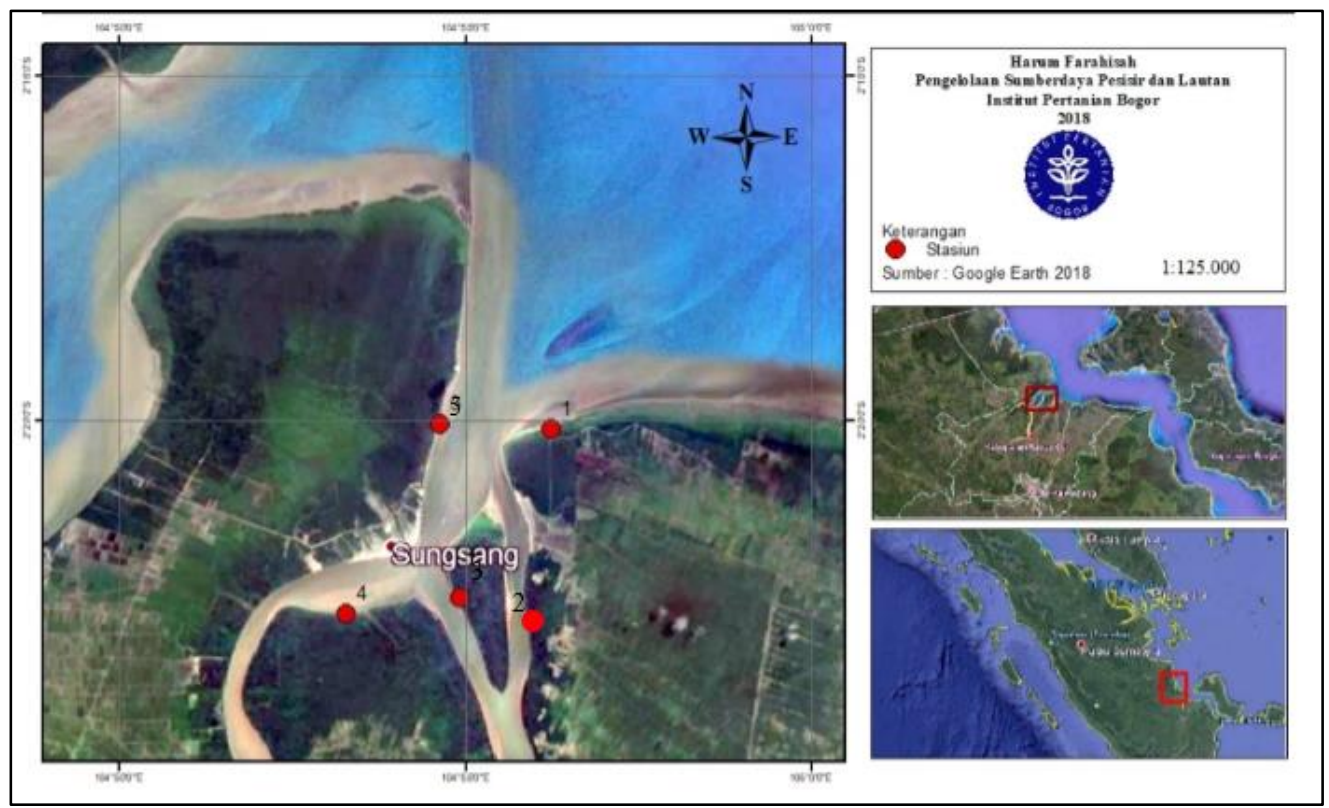

Gambar 1. Lokasi penelitian di wilayah muara Sungai Musi, Sumatera Selatan.

\subsection{Prosedur analisis data}

Persepsi dan partisipasi masyarakat didapatkan dengan pengisian kuesioner wawancara oleh responden yang dtentukan dengan metode purposive sampling sebanyak 30 orang. Responden terpilih merupakan masyarakat atau pihak yang memiliki keterkaitan dengan kawasan mangrove seperti nelayan, tokoh masyarakat, pemerintah desa dan pihak lainnya. Setelah itu dilakukan analisis secara deskriptif dari hasil wawancara yang diperoleh.

Analisis stakeholder juga dilakukan untuk mengidentifikasi kelompok stakeholder penting, menilai hubungan antar stakeholder dan mengetahui arti penting dan kekuatan relatifnya (Mumtas and Wichien 2013). Stakeholder yang diwawancarai adalah Dinas Kelautan dan Perikanan (DKP) Provinsi Sumatera Selatan, Dinas Kehutanan Provinsi Sumatera Selatan, Bappeda Provinsi Sumatera Selatan, Dinas Perikanan Kabupaten Banyuasin dan UPTD KPH Wilayah III Banyuasin. Menurut Suaedi (2013), dalam menentukan posisi stakeholder dapat dilihat dari kepentingan dan pengaruhnya dalam kerangka sistem keseluruhan. Selanjutnya, hasil wawancara stakeholder ditransformasikan menjadi data kuantitatif melalui scoring dengan membuat penilaian terhadap tingkat kepentingan dan pengaruh setiap stakeholder. Model indikator yang digunakan berdasarkan pada model yang dikembangkan oleh Abbas (2005) (Tabel 1). 
Tabel 1. Ukuran kuantitatif terhadap identifikasi pemetaan stakeholder.

\begin{tabular}{lccll}
\hline Variabel & Skor & $\begin{array}{c}\text { Total } \\
\text { skor }\end{array}$ & Kriteria & Keterangan \\
\hline \multirow{4}{*}{ Pengaruh } & 1 & 5 & Sangat rendah & Tidak mempengaruhi pengelolaan sumber daya \\
& 2 & $6-10$ & Rendah & Kurang mempengaruhi pengelolaan sumber daya \\
& 3 & $11-15$ & Cukup & Cukup mempengaruhi pengelolaan sumber daya \\
& 4 & $16-20$ & Tinggi & Mempengaruhi pengelolaan sumber daya \\
& 5 & $21-25$ & Sangat tinggi & Sangat mempengaruhi pengelolaan sumber daya \\
\hline \multirow{4}{*}{ Kepentingan } & 1 & 5 & Sangat rendah & Tidak bergantung pada keberadaan sumber daya \\
& 2 & $6-10$ & Rendah & Kurang bergantung pada keberadaan sumber daya \\
& 3 & $11-15$ & Cukup & Cukup bergantung pada keberadaan sumber daya \\
& 4 & $16-20$ & Tinggi & Bergantung pada keberadaan sumber daya \\
& 5 & $21-25$ & Sangat tinggi & Sangat bergantung pada keberadaan sumber daya \\
\hline
\end{tabular}

Nilai kepentingan dan pengaruh yang dimiliki setiap stakeholder berdasarkan hasil perhitungan kemudian dimasukkan ke dalam kuadran kepentingan dan pengaruh (Gambar 2).

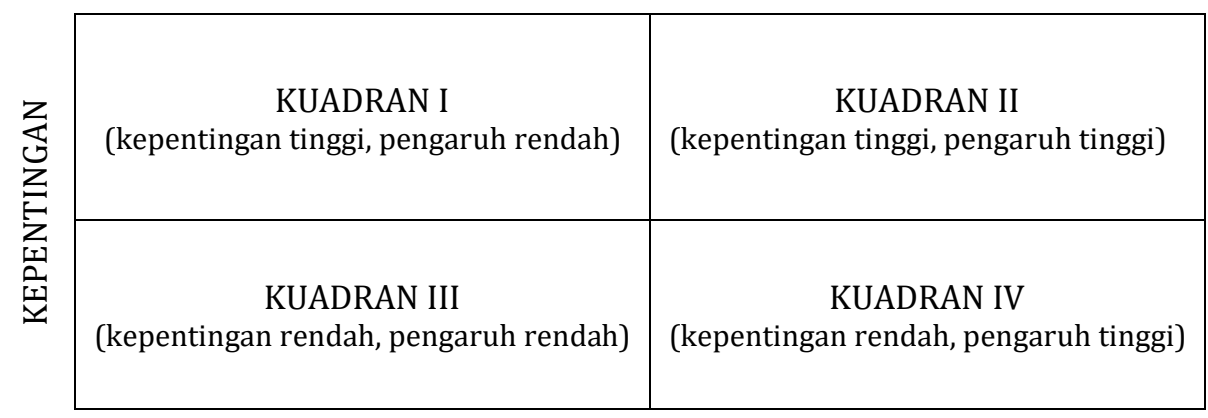

PENGARUH

Gambar 2. Kuadran analisis kepentingan dan pengaruh pemangku kepentingan.

\section{HASIL DAN PEMBAHASAN}

Kabupaten Banyuasin merupakan penyumbang emisi karbon terbesar kedua di Provinsi Sumatera Selatan yang berasal dari sektor berbasis lahan sebesar 1.087.147 TonCO $_{2}$ eq/tahun (Pemprov Sumsel 2018). Sumber emisi dari sektor penggunaan lahan berasal dari deforestasi, degradasi dan penurunan tegakan hijau, sehingga mempengaruhi lepasnya cadangan karbon ke udara. Pada penggunaan lahan, terdapat dua kategori penyumbang emisi yaitu penggunaan lahan secara terencana seperti proyek perkebunan, infrastruktur jalan atau pembukaan kawasan industri dan penggunaan lahan tidak terencana yang biasanya akibat bencana alam atau paling umum adalah illegal logging di kawasan hutan. Selain itu, dekomposisi lahan gambut juga ikut menyumbang terjadinya emisi di lingkungan yang biasanya dipicu oleh proses drainase dan kebakaran di areal gambut (Pemprov Sumsel 2018). 
Mangrove di muara Sungai Musi dimanfaatkan sebagai kayu bakar, pembuatan arang, bahan bangunan dan pembungkus masakan. Masyarakat memanfaatkan pesisir mangrove dengan menebarkan jaring untuk menangkap udang. Seiring dengan perkembangan zaman, pemanfaatan mangrove sebagai kayu bakar dan bahan bangunan sudah berkurang. Penebangan mangrove hanya terjadi saat masyarakat hendak membangun rumah atau mengadakan acara. Kawasan mangrove di muara Sungai Musi termasuk ke dalam wilayah pengelolaan hutan lindung berdasarkan KepMenHut Nomor 76 Tahun 2010 dan terjadi perubahan batas wilayah kawasan hutan lindung berdasarkan KepMenLHK Nomor 173 Tahun 2018.

\subsection{Persepsi dan partisipasi masyarakat}

Secara umum persepsi atau tanggapan masyarakat Desa Sungsang mengenai keberadaan kawasan mangrove di wilayah mereka adalah 100\% setuju. Sebanyak 90\% masyarakat setuju akan fungsi mangrove sebagai penyuplai udara segar dan 94\% masyarakat setuju bahwa mangrove berfungsi sebagai penyaring dan penahan air laut. Pengalaman masyarakat sendiri dan lingkungan tempat tinggalnya yang berada di sekitar ekosistem mangrove membuat mereka sadar akan fungsi dan peranan mangrove. Disamping itu, terdapat $16 \%$ masyarakat yang menganggap peranan mangrove dalam menurunkan emisi karbon kurang tepat (Gambar 3). Hal ini dapat disebabkan karena masyarakat masih belum paham akan fungsi ekologis mangrove dalam menyerap dan menyimpan karbon.

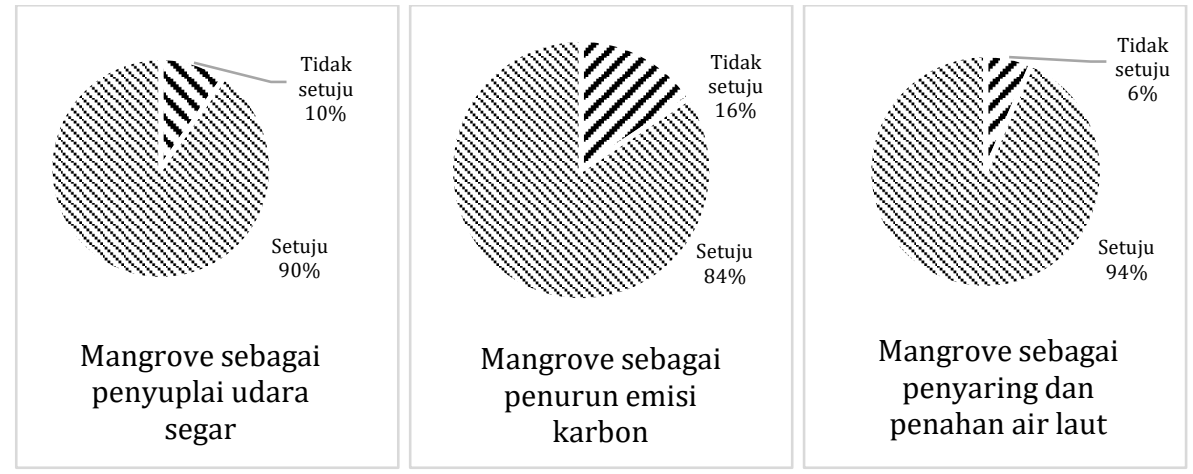

Gambar 3. Tanggapan masyarakat terhadap mangrove.

Partisipasi masyarakat dalam pengelolaan ekosistem mangrove dapat dilihat pada Gambar 4. Hasil analisis menunjukkan 91\% masyarakat setuju dengan adanya perwakilan masyarakat dalam pengelolaan ekosistem mangrove. Sebanyak 97\% masyarakat tidak setuju jika harus menerima tanpa ada pemberitahuan atau sosialisasi terlebih dahulu terkait pengelolaan mangrove. Lebih lanjut, 91\% masyarakat setuju untuk berpartisipasi dalam kegiatan 
pengelolaan mangrove. Selain itu, seluruh masyarakat setuju tentang kebijakan mengenai mangrove dikonsultasikan terlebih dahulu dengan masyarakat. Berdasarkan hal ini, dapat dilihat bahwa masyarakat ingin diikutsertakan dalam kebijakan mengenai ekosistem mangrove, baik dalam pemberitahuan atau konsultasi kebijakan maupun dalam partisipasi kegiatan pengelolaan mangrove. Akan tetapi, masyarakat secara umum juga tidak memiliki kapasitas untuk ikut merumuskan dan memutuskan kebijakan. Hal ini merupakan gap yang terjadi di masyarakat karena masyarakat merasa memiliki kewenangan untuk ekosistem mangrove di sekitarnya. Kondisi ini merupakan hal positif, karena dengan adanya rasa memiliki tersebut, masyarakat dapat lebih menjaga dan memperhatikan kondisi mangrove di lingkungan mereka. Partisipasi masyarakat dapat berupa kesadaran akan pentingnya ekosistem mangrove dengan tidak menebang pohon sembarangan, saling menegur, adanya hukuman bila terdapat sesama masyarakat yang melanggar, serta ikut serta dalam program pemerintah yang mengharuskan masyarakat berpartisipasi.

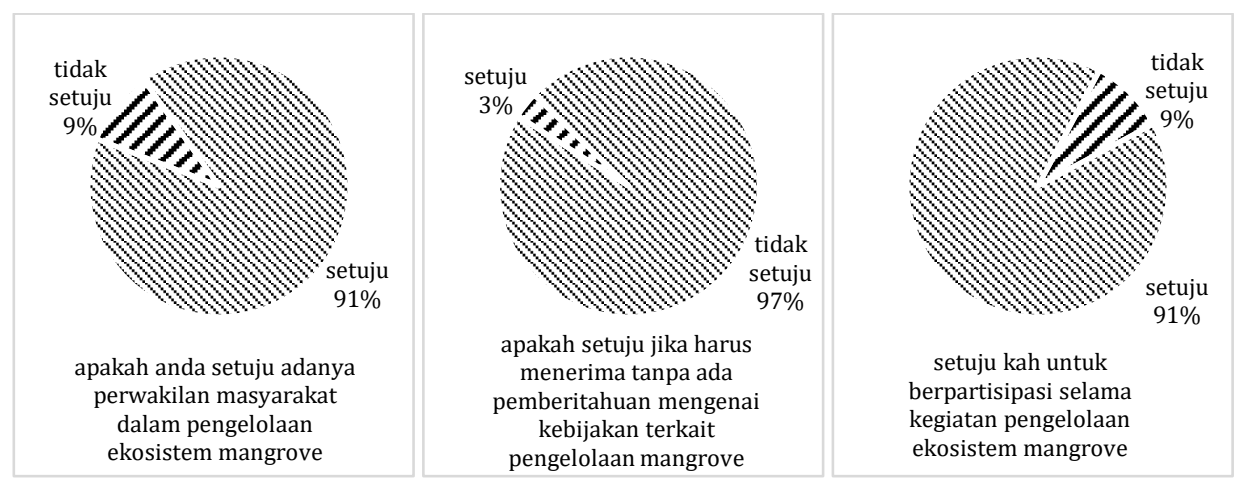

Gambar 4. Tingkat partisipasi masyarakat terhadap pengelolaan mangrove.

Persepsi dan partisipasi masyarakat terhadap pengelolaan mangrove di muara Sungai Musi cenderung tinggi. Hal yang serupa juga terjadi di kawasan hutan mangrove Tugurejo (KHMT), masyarakat di KHMT memiliki persepsi positif terhadap wilayah mangrove, sehingga berpengaruh positif pula terhadap partisipasi mereka dalam pengelolaan mangrove. Masyarakat di KHMT memiliki keinginan yang tinggi untuk melestarikan, menjaga dan berharap akan adanya upaya perlindungan dan perbaikan KHMT (Diarto et al. 2012). Menurut penelitian Hakim dan Darusman (2015), masyarakat di Wonorejo juga memiliki tingkat persepsi yang tinggi terhadap kawasan mangrove. Hal ini menunjukkan bahwa masyarakat mempunyai persepsi yang benar terhadap kawasan mangrove, serta mendukung keberadaan dan kelestariannya. Akan tetapi, partisipasi masyarakat dalam pengelolaan mangrove di Wonorejo cenderung rendah dimana masyarakat kurang terlibat atau dilibatkan. 


\subsection{Analisis stakeholder}

Pemetaan stakeholder didapatkan dari hasil interview pengelolaan potensi sumber daya dalam ekosistem mangrove berdasarkan tingkat kepentingan dan pengaruh. UPTD KPH Wilayah III Banyuasin, Dinas Kehutanan Provinsi Sumatera Selatan dan DKP Provinsi Sumatera Selatan memiliki kepentingan dan pengaruh yang tinggi (Kuadran II) (Gambar 5). Stakeholder yang berada pada Kuadran II merupakan key player yang perlu dilibatkan secara aktif dan penuh, termasuk pada saat evaluasi strategi baru (Oktavia dan Saharuddin 2013). UPTD KPH Wilayah III Banyuasin adalah stakeholder yang memiliki kepentingan dan pengaruh paling tinggi. UPTD ini adalah salah satu unit organisasi teknis pada Dinas Kehutanan Provinsi Sumatera Selatan yang mengelola kawasan hutan dengan luas \pm 70.290 ha (KPHL 2015).

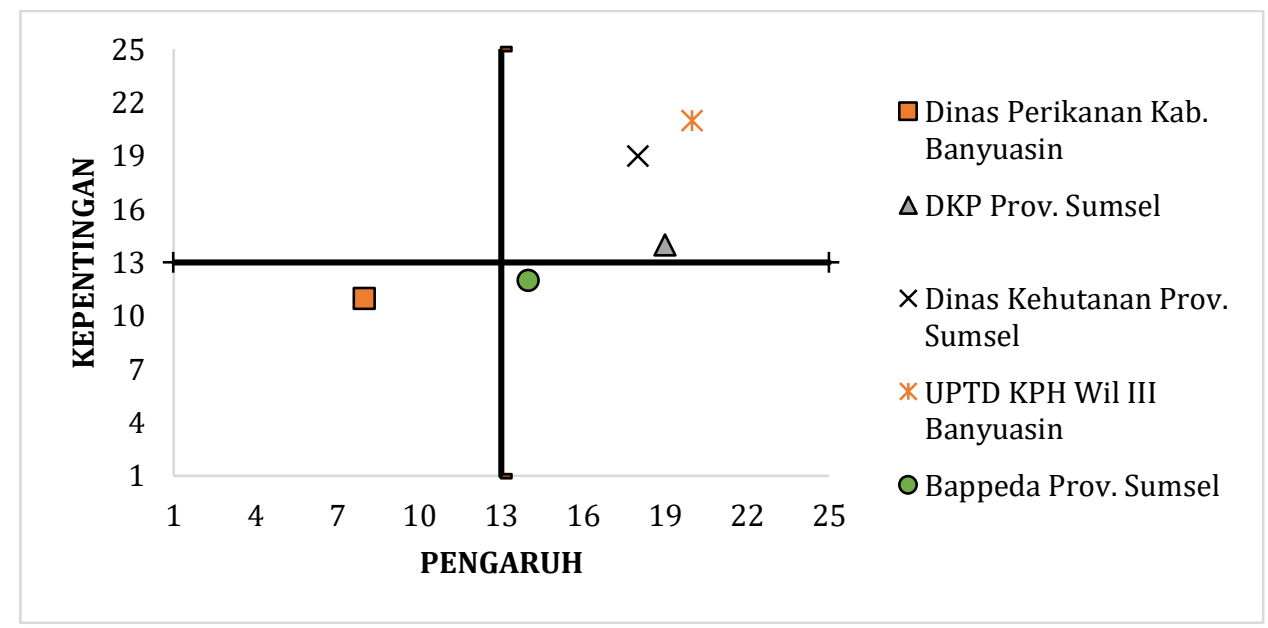

Gambar 5. Kuadran analisis stakeholder.

Bappeda Provinsi Sumatera Selatan memiliki tingkat kepentingan rendah, namun memiliki pengaruh yang tinggi (Kuadran IV) yang disebut juga sebagai context setter. Menurut Oktavia dan Saharuddin (2013), stakeholder pada Kuadran IV harus dikelola dan dipantau dengan baik karena keberadaannya dapat mendatangkan risiko. Hubungan baik dengan stakeholder tersebut perlu terus dibina agar dapat terus berperan aktif dalam pencapaian tujuan, sehingga segala informasi yang dibutuhkan hendaknya tetap diberikan. Kegiatan pengelolaan atau pembangunan oleh Bappeda Provinsi Sumatera Selatan di Kabupaten Banyuasin berupa Pelabuhan Tanjung Api-api dan Tanjung Carat, serta kawasan ekonomi khusus. Meskipun tidak memiliki pengelolaan terkait mangrove, Bappeda Provinsi Sumatera Selatan memiliki pengaruh, berinteraksi dan bekerja sama dengan instansi lain yang berkaitan dengan wilayah muara Sungai Musi (Kabupaten Banyuasin) dan kegiatan pengelolaan ekosistem 
mangrove. Kuadran III diisi oleh Dinas Perikanan Kabupaten Banyuasin yang memiliki pengaruh dan kepentingan rendah yang disebut juga sebagai crowd/bystander. Dinas Perikanan tidak memiliki pengelolaan terkait ekosistem mangrove/pesisir di muara Sungai Musi, akan tetapi masih tetap berpartisipasi dalam forum untuk membahas rencana pengelolaan dengan stakeholder lainnya.

Idealnya seluruh stakeholder hendaknya mempunyai kepentingan dan pengaruh yang tinggi (termasuk dalam key players). Sektor kehutanan dan perikanan/kelautan hendaknya saling berkolaborasi dalam pengelolaan ekosistem mangrove karena sama-sama memiliki kepentingan dan wewenang terkait mangrove. Kondisi mangrove yang baik akan meningkatkan produksi perikanan seperti udang dan kepiting, sehingga ekonomi masyarakat perikanan juga akan semakin meningkat. Dinas Perikanan Kabupaten Banyuasin hendaknya memiliki kepentingan dan pengaruh yang tinggi seperti DKP Provinsi Sumatera Selatan karena merupakan stakeholder paling dekat dan relatif lebih mengetahui kondisi wilayah pesisir muara Sungai Musi. Pembangunan di kawasan pesisir Sungai Musi seperti kawasan ekonomi khusus atau pelabuhan Tanjung Api-api juga dapat mempengaruhi kondisi ekosistem mangrove di muara Sungai Musi, sehingga Bappeda juga hendaknya memiliki kepentingan dan pengaruh yang tinggi untuk mengendalikan pembangunan dan melindungi ekosistem mangrove. Seperti halnya pada kajian di Kuala Langsa oleh Zurba (2017), stakeholder yang diklasifikasikan sebagai key players dan berperan aktif adalah Dinas Kelautan dan Perikanan, Dinas Pariwisata, Dinas Kehutanan dan Bappeda. Oleh karena itu, perlu ditingkatkan koordinasi tiap stakeholder melalui pertemuan rutin sebagai sarana komunikasi, koordinasi dan informasi dalam penyusunan rencana, pelaksanaan, hingga pemantauan dan evaluasi kegiatan.

\subsection{Pengelolaan terkait emisi karbon}

Upaya-upaya pengelolaan untuk mengurangi dampak perubahan iklim adalah dengan mengurangi emisi karbon dan meningkatkan penyerapannya. Pengelolaan ekosistem mangrove dalam menurunkan emisi karbon atau gas rumah kaca perlu dilakukan dengan membangun kerja sama dan koordinasi antar stakeholder, karena tidak cukup hanya satu stakeholder saja. Pertemuan berkala antar stakeholder dapat menjadi wadah diskusi terkait strategi pengelolaan penurunan emisi karbon dan dapat mempermudah koordinasi mulai dari perencanaan hingga pelaksanaan program kerja. Selain itu, upaya peningkatan kapasitas sumber daya manusia terkait emisi dan perubahan iklim akibat gas rumah kaca hingga kondisi lingkungan dapat mendorong masyarakat untuk ikut serta dalam pengelolaan mangrove. Daerah ekosistem mangrove merupakan sumber penghasilan masyarakat nelayan, sehingga semua stakeholder hingga masyarakat perlu memprioritaskan kegiatan konservasi. 
Beberapa rekomendasi pengelolaan untuk peningkatan cadangan karbon diantaranya melalui:

- Penyediaan tenaga ahli dalam sosialisasi dan pengukuran data karbon.

- Pembuatan peraturan daerah mengenai pengelolaan dan harga karbon.

- Pemberdayaan dan peningkatan pengetahuan masyarakat sekitar mengenai karbon dan ekosistem mangrove melalui penyuluhan atau pelatihan terkait emisi karbon atau perubahan iklim seperti global warming. Masyarakat akan menjadi lebih paham tentang kondisi lingkungannya dan sadar pentingnya menjaga mangrove dan memanfaatkan secara bijak.

- Rehabilitasi hutan dan lahan, khususnya rehabilitasi mangrove.

- Pengembangan hasil hutan non kayu.

- Pengembangan teknik budidaya agroforestri dan konservasi tanah dan air.

- Pencegahan penurunan cadangan karbon, dapat berupa perlindungan dan konservasi sumber daya alam (khususnya hutan mangrove).

- Pencegahan dan pengendalian kebakaran hutan dan lahan.

Beberapa kawasan yang telah melakukan pengelolaan hutan untuk mengurangi emisi karbon adalah kawasan Hutan Adat Rumbio, Provinsi Riau dan Hutan Lindung Yapase, Papua. Masyarakat di daerah tersebut mendukung daerah mereka sebagai inisiator pengurangan emisi dari deforestasi dan degradasi hutan (REDD+). Masyarakat Hutan Adat Rumbio telah memiliki lembaga khusus yakni badan pengelola hutan larangan adat Rumbio. Lembaga ini memiliki rencana pengelolaan selama 10 tahun, serta telah memasukkan pemanfaatan jasa lingkungan dan perdagangan karbon di dalam program kegiatannya. Masyarakat Desa Yapase juga membentuk kelompok kerja untuk menjaga kelestarian hutan dan sumber penghasilan masyarakat. Beberapa anggota kelompok kerja ini juga telah diberikan pelatihan tentang pengukuran karbon (Alviya et al. 2018).

\section{KESIMPULAN DAN SARAN}

Lebih dari 90\% masyarakat mengetahui keberadaan dan fungsi mangrove dan setuju berpartisipasi terhadap berbagai kebijakan mengenai pengelolaan mangrove. Semua stakeholder hendaknya didorong menjadi key player dalam pengelolaan mangrove di muara Sungai Musi dan perlu keterpaduan antara stakeholder mulai dari perencanaan dan perumusan hingga pelaksanaan program. Disarankan untuk kedepannya agar menjaga dan melakukan rehabilitasi mangrove di muara Sungai Musi dan membentuk lembaga atau kelompok kerja yang melibatkan masyarakat untuk mendukung pengelolaan mangrove sebagai salah satu upaya mitigasi emisi karbon. 


\section{DAFTAR PUSTAKA}

Abbas R. 2005. Mekanisme perencanaan partisipasi pemangku kepentingan Taman Nasional Gunung Rinjani [Disertasi]. Program Studi Pengelolaan Sumberdaya Alam dan Lingkungan, Sekolah Pascasarjana, IPB University. Bogor.

Adame MF, Kauffman JB, Medina I, Gamboa JN, Torres O, Caamal JP, Reza M and Herrera-Silveira JA. 2013. Carbon stocks of tropical coastal wetlands within the karstic landscape of the Mexican Caribbean. PloS ONE 8(2):1-13.

Alviya I, Muttaqin MZ, Salminah M dan Hamdani FAU. 2018. Upaya penurunan karbon berbasis masyarakat di hutan berfungsi lindung. Jurnal Analisis Kebijakan Kehutanan 15(1):19-37.

[BRPPU] Balai Riset Perikanan Perairan Umum. 2010. Perikanan perairan Sungai Musi Sumatera Selatan. BRPPU, Pusat Penelitian Pengelolaan Perikanan dan Konservasi Sumber Daya Ikan, Badan Penelitian dan Pengembangan Kelautan dan Perikanan, Kementerian Kelautan dan Perikanan. Palembang. Diarto, Hendrarto B dan Suryoko S. 2012. Partisipasi mayarakat dalam pengelolaan lingkungan kawasan hutan mangrove Tugurejo di Kota Semarang. Jurnal Ilmu Kelautan 10 (1):1-7.

Donato DC, Kauffman JB, Murdiyarso D, Kurnianto S, Stidham M and Kanninen M. 2011. Mangroves among the most carbon-rich forests in the tropics. Nature Geoscience 4:293-297.

Hakim AM dan Darusman D. 2015. Persepsi, sikap, dan partisipasi masyarakat dalam pengelolaan hutan mangrove di Wonorejo, Surabaya, Jawa Timur. Bonorowo Wetlands 5(2):85-93.

Kauffman J, Heider C, Cole T, Dwire K and Donato D. 2011. Ecosystem carbon stocks of Micronesian mangrove forests. Wetlands 31:343-352.

KepMenHut (Keputusan Menteri Kehutanan) Nomor 76 Tahun 2010 tentang penetapan KPHL dan KPHP di Provinsi Sumatera Selatan.

KepMenLHK (Keputusan Menteri Lingkungan Hidup dan Kehutanan) Nomor 173 Tahun 2018.

[KPHL] Kesatuan Pengelolaan Hutan Lindung. 2015. Rencana pengelolaan hutan jangka panjang (RPHJP) kesatuan pengelolaan hutan lindung (KPHL) unit I Banyuasin. KPHL Unit I Banyuasin, Dinas Kehutanan dan Perkebunan Kabupaten Banyuasin. Banyuasin.

Melki and Isnaini. 2014. Carbon stocks in mangrove ecosystems of Musi and Banyuasin Estuarine, South Sumatra Province. Ilmu Kelautan 19(3):131138.

Mumtas M and Wichien C. 2013. Stakeholder analysis for sustainable land marked management of Pak Phanang River Basin, Thailand. Procedia Social and Behavioral Science 91:349-356. 
Purwiyanto AIS and Agustriani F. 2016. Asessment of carbon status in marine protected area of Payung Island waters, South Sumatera Province, Indonesia. Ilmu Kelautan 22(1):1-6.

Oktavia S dan Saharuddin. 2013. Hubungan peran stakeholders dengan partisipasi masyarakat dalam program agropolitan desa Karacak Kecamatan Leuwiliang Kabupaten Bogor. Jurnal Sosiologi Pedesaan 1(3):231-246.

[Pemprov Sumsel] Pemerintah Provinsi Sumatera Selatan. 2018. Rencana aksi daerah (RAD) penurunan emisi gas rumah kaca (GRK) Provinsi Sumatera Selatan tahun 2010-2030. Pemprov Sumsel. Palembang.

Rachmawati D, Setyobudiandi I dan Hilmi E. 2014. Potensi estimasi karbon tersimpan pada vegetasi mangrove di wilayah pesisir Muara Gembong Kabupaten Bekasi. Omni-Akuatika 10(2):85-91.

Suaedi. 2013. Metode kuantitatif untuk analisis kebijakan. IPB Press. Bogor.

Suman DO. 2018. Mangrove management: challenges and guidelines. In: Perillo GME, Wolanski E, Cahoon DR and Hopkinson CS. Coastal wetlands, second edition: an integrated and ecosystem approach. Elsevier.

Tue NT, Dung LV, Nhuan MT and Omori K. 2014. Carbon storage of a tropical mangrove forest in Mui Ca Mau National Park, Vietnam. Catena 121:119126.

Zurba N. 2017. Pengelolaan potensi sumberdaya ekosistem mangrove di Kuala Langsa, Aceh [Tesis]. Departemen Manajemen Sumberdaya Perairan, Fakultas Perikanan dan Ilmu Kelautan, IPB University. Bogor. 